\begin{tabular}{|c|c|}
\hline Title & $\begin{array}{l}\text { Elucidation of the local structure of active titanium(iv) sites on silica based phase boundary catalysts for al kene } \\
\text { epoxidation with aqueous hydrogen peroxide }\end{array}$ \\
\hline Author(s) & Ikeue, Keita; Ikeda, Shigeru; W atanabe, A tsushi; Ohtani, Bunsho \\
\hline Citation & $\begin{array}{l}\text { Physical Chemistry Chemical Physics, 6(9), 2523-2528 } \\
\text { https://doi.org/10.1039/0316818b }\end{array}$ \\
\hline Issue Date & 2004 \\
\hline Doc URL & http:/hdl.handle.net/2115/48673 \\
\hline Rights & $\begin{array}{l}\text { Phys. Chem. Chem. Phy s., } 2004,6,2523-2528 \\
\text { - Reproduced by permission of the PCCP Owner Societies }\end{array}$ \\
\hline Type & article (author version) \\
\hline File Information & PCCP6_2523.pdf \\
\hline
\end{tabular}

Instructions for use 


\author{
Bunsho Ohtani \\ Catalysis Research Center, Hokkaido University, Sapporo 001-0021, Japan \\ TEL: +81-11-706-9132 FAX: +81-706-9133 \\ E-mail: ohtani@cat.hokudai.ac.jp
}

\title{
Elucidation of the local structure of active titanium(IV) sites on silica-based phase-boundary catalysts for alkene epoxidation with aqueous hydrogen peroxide
}

Keita Ikeue, ${ }^{\ddagger}$ Shigeru Ikeda, ${ }^{\ddagger \dagger}$ Atsushi Watanabe,${ }^{\S}$ Bunsho Ohtani ${ }^{*}{ }^{\S}$

¥ "Conversion and Control by Advanced Chemistry"

PRESTO, Japan Science and Technology Agency (JST), Japan

$\uparrow$ Research Center for Solar Energy Chemistry, Osaka University, Toyonaka 560-8531, Japan

${ }^{\S}$ Catalysis Research Center, Hokkaido University, Sapporo 001-0021, Japan

Structural and functional aspects of active titanium sites for phase boundary catalytic (PBC) epoxidation of 1-octene with hydrogen peroxide $\left(\mathrm{H}_{2} \mathrm{O}_{2}\right)$ were investigated in detail using X-ray absorption fine structure (XAFS) analysis and diffuse reflectance (DR) spectroscopy. By analysis of the Ti K-edge X-ray absorption near edge fine structure (XANES) spectra of several titanium-loaded silica catalysts, the ratio of the amount of 4-coodinated titanium oxide $\left(\mathrm{T}_{\mathrm{tet}}\right)$ to that of a 6-coordinated one $\left(\mathrm{T}_{\text {oct }}\right)$ was determined. Monotonic increments of catalytic activity for epoxide production and efficiency of $\mathrm{H}_{2} \mathrm{O}_{2}$ utilization with the ratio $\mathrm{T}_{\text {tet }} /\left(\mathrm{T}_{\text {tet }}+\mathrm{T}_{\text {oct }}\right)$ revealed that the highly active catalysts mainly include $\mathrm{T}_{\text {tet }}$ but not 
$\mathrm{T}_{\text {oct }}$ DR spectra of samples with external surfaces partially covered with alkylsilyl groups indicated that there are at least two kinds of $\mathrm{T}_{\text {tet }}$ sites with different ligands. One site anchors an acidic hydroxyl $\left(\mathrm{T}_{\text {tet }}(\mathrm{OH})\right)$, giving absorption centered at the wavelength of ca. $230 \mathrm{~nm}$ and the other, exhibiting an absorption peak at the wavelength of ca. $210 \mathrm{~nm}$, is directly attached to an alkylsilyl group ( $\left.\mathrm{T}_{\text {tet }}(\mathrm{OSiR})\right)$ formed via reaction of an acidic hydroxyl of $\mathrm{T}_{\mathrm{tet}}(\mathrm{OH})$ with an alkylsilane regent. Since the catalysts have both an alkylsilyl-grafted hydrophobic surface and a hydroxyl-terminated hydrophilic surface, it is postulated that the former is located on both hydrophilic $\left(\mathrm{T}_{\text {tet }}(\mathrm{OH}, \mathrm{w})\right)$ and hydrophobic $\left(\mathrm{T}_{\text {tet }}(\mathrm{OH}, \mathrm{o})\right)$ surfaces and the latter, $\mathrm{T}_{\text {tet }}(\mathrm{OSiR})$, exists only on the hydrophobic surface. From analyses of catalytic activities of several catalysts with different distributions of these $T_{\text {tet }}$ sites, both $\mathrm{T}_{\text {tet }}(\mathrm{OH}, \mathrm{o})$ and $\mathrm{T}_{\text {tet }}(\mathrm{OSiR})$ sites on the hydrophobic surface were proved to be active, while $\mathrm{T}_{\text {tet }}(\mathrm{OH}, \mathrm{w})$ on the hydrophilic surface did not work for the present PBC system. Among the sites on the hydrophobic surface, moreover, it was found that a $\mathrm{T}_{\text {tet }}(\mathrm{OSiR})$ site acted as a more effective site for selective epoxidation when compared with $\mathrm{T}_{\text {tet }}(\mathrm{OH}, \mathrm{o})$, which induced ring-opening of epoxide to give a by-product, 1,2-octanediol. 


\section{Introduction}

In the known chemical processes in catalytic oxidation, liquid-phase epoxidation of alkene is one of most important reactions for producing fine organic chemicals and their precursors. ${ }^{1}$ From the viewpoint of the establishment of environmentally benign and ecologically more acceptable chemical processes, the use of aqueous hydrogen peroxide $\left(\mathrm{H}_{2} \mathrm{O}_{2}\right)$ as an oxidizing agent is desirable because of its low toxicity and environmentally benign characteristics, i.e., only releasing water as a by-product. However, the use of $\mathrm{H}_{2} \mathrm{O}_{2}$ in liquid-phase epoxidation reactions sometimes requires the addition of a co-solvent and/or agitation of the mixture to make an emulsion for achieving effective interaction of $\mathrm{H}_{2} \mathrm{O}_{2}$ with catalysts and substrates because $\mathrm{H}_{2} \mathrm{O}_{2}$ is supplied as an aqueous solution and reaction substrates are generally immiscible with water. ${ }^{2-4}$

Recently, we have proposed a novel catalytic system, named phase-boundary catalysis (PBC), for driving the liquid-phase oxidation of water-immiscible organic compounds using aqueous $\mathrm{H}_{2} \mathrm{O}_{2}$ and a solid catalyst without the requirement of a co-solvent or agitation. ${ }^{5,6}$ We have reported that titanium oxide-loaded $\mathrm{NaY}$ zeolite particles with external surfaces partially covered with alkylsilyl groups were spontaneously assembled at the liquid-liquid phase boundary and efficiently catalyzed epoxidation of straight-chain alkenes at room temperature even without agitation. It has been also revealed through fluorescence microscopic observation of the NaY particles selectively modified with fluorescence dye that the attached alkylsilyl groups were distributed only on one side of the external surface of the $\mathrm{NaY}$ particle, resulting in a bimodal surface structure, i.e., one side of the external surface is hydrophilic and the other is hydrophobic. ${ }^{7}$ To the best of our knowledge, there have been no reported examples of a solid catalyst $-\mathrm{H}_{2} \mathrm{O}_{2}$ system similar to this PBC system using bimodal catalyst particles. 
The phenomenological aspects of PBC have been reported in detail in our previous papers $^{6}$ and the bimodal characteristics have also been discussed in detail, ${ }^{7}$ but the structure of active sites has remained unclear. It is necessary to clarify and control the local structure of active species in catalysts for further applications of PBC to various substrates. In the present study, therefore, we focused our attention on the local structure of titanium oxide species on support materials to obtain information that will be useful for the design and preparation of suitable bimodal particles for PBC.

\section{Experimental}

Silica (Degussa AEROSIL 200) loaded with various amounts of titanium(IV) oxide species $\left(\mathrm{C}_{\mathrm{Ti}} / \mu \mathrm{mol} \mathrm{g}{ }^{-1}\right)$ was prepared by the following procedure. Three grams of silica was added to $100 \mathrm{~cm}^{3}$ of 2-propanol solution of titanium(IV) tetraethoxide $\left(\mathrm{Ti}(\mathrm{OEt})_{4}\right)$ under a dry argon atmosphere. The amount of $\mathrm{Ti}(\mathrm{OEt})_{4}$ was adjusted in order to synthesize samples with different $\mathrm{C}_{\mathrm{Ti}}$. After stirring the suspension at room temperature for $3 \mathrm{~h}$, a solid part was collected by centrifugation, dried at $383 \mathrm{~K}$ for $2 \mathrm{~h}$ under vacuum, and calcined at $773 \mathrm{~K}$ for $6 \mathrm{~h}$. The as-prepared samples are called w- $\mathrm{Ti}\left(\mathrm{C}_{\mathrm{Ti}}\right) / \mathrm{SiO}_{2}$, e.g., w- $\mathrm{Ti}(44) / \mathrm{SiO}_{2}$ represents a sample containing $44 \mu \mathrm{mol}$ $\mathrm{g}^{-1}$ of titanium atom. The titanium content $\left(\mathrm{C}_{\mathrm{Ti}}\right)$ was determined by colorimetric analysis of the samples using 1,2-dihydroxy-3,5-benzenedisulfonic acid, disodium salt (Tiron) as a colorimetric agent. Bimodal particles whose external surfaces were partially covered with alkylsilyl groups were prepared as follows. To $10 \mathrm{~cm}^{3}$ of toluene containing $1 \mathrm{mmol}$ of n-octadecyltrimethoxysilane (ODMS), $0.5 \mathrm{~g}$ of $\mathrm{w}-\mathrm{Ti}\left(\mathrm{C}_{\mathrm{Ti}}\right) / \mathrm{SiO}_{2}$ thoroughly mixed with $16.7 \mathrm{wt} \%$ of water was added, and the suspension was shaken for $2 \mathrm{~min}$ at room temperature. After the addition of triethylamine $(1 \mathrm{mmol})$, the suspension was further shaken for $10 \mathrm{~min}$ at room temperature. Then the solid was collected by centrifugation and dried at $383 \mathrm{~K}$ for 
$2 \mathrm{~h}$ under vacuum. The thus-prepared samples were labeled w/o-Ti $\left(\mathrm{C}_{\mathrm{Ti}}\right) / \mathrm{SiO}_{2}$. A sample whose external surfaces were covered with a silica shell was also prepared by the reaction of dry w-Ti(158)/ $\mathrm{SiO}_{2}$ and ODMS followed by calcination at $773 \mathrm{~K}$ for $6 \mathrm{~h}$ to remove the organic moieties.

In a typical experiment for epoxidation of 1-octene with aqueous hydrogen peroxide, 1-octene $\left(4 \mathrm{~cm}^{3}\right), 30 \%$ aqueous hydrogen peroxide $\left(1 \mathrm{~cm}^{3}\right)$ and catalyst particles $(50 \mathrm{mg})$ were placed in a glass tube $(16 \mathrm{~mm}$ in diameter) and kept at 298 $\mathrm{K}$ for $20 \mathrm{~h}$. In order to remove appreciable impurities, 1-octene (Kanto Chemical) was treated with basic alumina (Merck) before use. Reaction products were analyzed by a Shimadzu GC-14B gas chromatograph equipped with a DB-1 column (J\&W) and an FID detector.

Diffuse reflection (DR) spectra were recorded on a Hamamatsu Photonics C7473-6 Photonic Multi-Channel Analyzer, and the reflection data were converted to Kubelka-Munk (KM) function. Before the DR measurements, all samples were dried at $573 \mathrm{~K}$ or $423 \mathrm{~K}$ for $3 \mathrm{~h}$ under vacuum and the data were collected at room temperature under vacuum. XAFS measurements were carried out at the BL-9A facility $^{8}$ of the Photon Factory at High Energy Acceleration for Research Organization, Tsukuba, Japan (Proposal \#2002G272). The X-ray source from a 2.5 $\mathrm{GeV}$ electron-storage ring was monochromatized using an $\mathrm{Si}(111)$ double-crystal monochromator. The $\mathrm{Ti}$ K-edge absorption spectra were recorded in the fluorescence mode at $298 \mathrm{~K}$ after pretreatment of the samples at $573 \mathrm{~K}$ for $3 \mathrm{~h}$ under vacuum. The XANES spectra were analyzed using a Rigaku REX 2000 program.

\section{Results and Discussion}

\section{Catalytic activity for epoxidation of 1-octene.}


In the case of $\mathrm{NaY}$ zeolite, which was used as a support in our previous studies, ${ }^{5-7}$ several factors such as pore structure and acid property might influence both structural characteristics of active sites and catalytic properties. Therefore, in order to determine the pure effects of local structure of active sites on reactivity and selectivity, nonporous silica was selected as a model support material. Table 1 summarizes the yields of products from the mixture of 1-octene and aqueous $\mathrm{H}_{2} \mathrm{O}_{2}$ in the presence of titanium-loaded silica samples. Upon dispersion in the two-phase mixture, w/o- $\mathrm{Ti}\left(\mathrm{C}_{\mathrm{Ti}}\right) / \mathrm{SiO}_{2}$ was spontaneously assembled at the liquid-liquid phase boundary (Fig. 1a) and showed activity for epoxidation to give 1,2-epoxyoctane as a main or a sole product even without agitation (entries 1 and 2). Note that, probably due to the successive ring-opening reaction (see below) with stirring, w/o- $\mathrm{Ti}(333) / \mathrm{SiO}_{2}$ with a relatively high titanium content gave less than half yield of epoxide with stirring (entry 2). ${ }^{6}$ On the other hand, the w-Ti(158)/ $/ \mathrm{SiO}_{2}$ sample, which preferentially disperses in the aqueous phase as shown in Fig. 1b, showed an appreciable, but quite low, level of activity even with stirring (entry 3). Since these trends are similar to the previous results obtained by using titanium(IV) oxide-loaded $\mathrm{NaY}$ zeolite catalysts, the present w/o- $\mathrm{Ti}\left(\mathrm{C}_{\mathrm{Ti}}\right) / \mathrm{SiO}_{2}$-based system is also an example of phase-boundary catalysis, though details of the distribution of surface-covering alkylsilyl groups and the bimodal unsymmetrical surface characteristics of silica particles were not discussed here. ${ }^{9}$ Since it seems that w/o- $\mathrm{Ti}\left(\mathrm{C}_{\mathrm{Ti}}\right) / \mathrm{SiO}_{2}$ dose not require mechanical agitation, the catalytic reactions reported in this paper were carried out without agitation unless otherwise stated.

Table 2 summarizes dependence of the catalytic activity of w/o- $\mathrm{Ti}\left(\mathrm{C}_{\mathrm{Ti}}\right) / \mathrm{SiO}_{2}$ for 1-octene epoxidation on $\mathrm{C}_{\mathrm{Ti}}$. For samples with relatively low $\mathrm{C}_{\mathrm{Ti}}$ (entries 1-3), 1,2-epoxyoctane was produced as a sole product and its yield increased with increase in $\mathrm{C}_{\mathrm{Ti}}$, while by-products, e.g., 1,2-octanediol, appeared in reaction with catalysts containing a relatively large amount of titanium (entries 4 and 5) and the 
epoxide yield was reduced along with $\mathrm{C}_{\mathrm{Ti}}$. Moreover, turnover number (TON) based on molar amount of titanium atom and efficiency of $\mathrm{H}_{2} \mathrm{O}_{2}$ utilization $\left(\mathrm{E}_{\mathrm{fH} 2 \mathrm{O} 2}\right)$, defined as percent proportion of $\mathrm{H}_{2} \mathrm{O}_{2}$ used for epoxide production among the total consumption of $\mathrm{H}_{2} \mathrm{O}_{2}$, decreased gradually with increase in $\mathrm{C}_{\mathrm{Ti}}$. Since structure and dispersibility of $\mathrm{Ti}$ on silica surfaces may depend on its content, the observed $\mathrm{C}_{\mathrm{Ti}}$ dependence might be induced by such structural alteration of titanium sites. Thus, the difference in local structure of active sites between these catalysts will be discussed in the following sections.

\section{Correlation between coordination number of Ti sites and catalytic activity.}

Figure 2 shows typical DR spectra of $\mathrm{w}-\mathrm{Ti}\left(\mathrm{C}_{\mathrm{Ti}}\right) / \mathrm{SiO}_{2}$ with different values of $\mathrm{C}_{\mathrm{Ti}}$. All of the samples gave absorption in the ultraviolet region below ca. $300 \mathrm{~nm}$ with a peak at ca. $230-240 \mathrm{~nm}$. Since the original silica has no photoabsorption in this wavelength range and, qualitatively, the intensity of absorption seems to increase with increase in $\mathrm{Ti}$ content (Fig. 2a), the absorption in all samples should be assigned to loaded titanium species. By a comparison of shapes of the absorption spectra normalized by KM function at $230 \mathrm{~nm}$ (Fig. 2b), it was revealed that these spectra tended to expand to a longer wavelength range with increase in $\mathrm{C}_{\mathrm{Ti}}$.

According to the literature, ${ }^{10-13}$ absorption at a wavelength around $200-250 \mathrm{~nm}$ is assigned to ligand-to-metal charge transfer (LMCT) from oxygen atoms to $\mathrm{Ti}^{4+}$ of 4-coordinated titanium oxide species $\left(\mathrm{T}_{\text {tet }}\right)$, and absorption in a longer wavelength region (ca. 250-290 $\mathrm{nm}$ ) is attributed to aggregated 6-coordinated titanium oxide species $\left(\mathrm{T}_{\mathrm{oct}}\right)$. Therefore, it is presumed that the titanium sites on the present samples were a mixture of $\mathrm{T}_{\text {tet }}$ and $\mathrm{T}_{\text {oct }}$ and that their ratio depended strongly on the Ti content (see below).

Figure 3 shows the Ti K-edge XANES spectra of selected $\mathrm{w}-\mathrm{Ti}\left(\mathrm{C}_{\mathrm{Ti}}\right) / \mathrm{SiO}_{2}$ samples. Spectra of crystalline titanium(IV) oxide $\left(\mathrm{TiO}_{2}\right.$, Degussa P25) and TS-1 
zeolite are also shown (Figs. 3a and 3b) as typical examples of $\mathrm{T}_{\text {tet }}$ and $\mathrm{T}_{\text {oct }}$, respectively. The XANES spectra have several well-defined peaks; TS-1, which includes mainly $\mathrm{T}_{\text {tet }}$, exhibited an intense single preedge peak at $4969.5 \mathrm{eV}$, while three characteristic weak preedge peaks appeared for bulk $\mathrm{TiO}_{2}$ composed of $\mathrm{T}_{\text {oct}}$. As is expected from above results of the above-described DR spectra, w- $\mathrm{Ti}\left(\mathrm{C}_{\mathrm{Ti}}\right) / \mathrm{SiO}_{2}$ showed spectral characteristics of both $\mathrm{T}_{\text {tet }}$ and $\mathrm{T}_{\text {oct }}$ In order to quantify $\mathrm{T}_{\text {tet }}$ and $\mathrm{T}_{\text {oct }}$ in the samples, the ratio of $\mathrm{T}_{\text {tet }}$ to $\mathrm{T}_{\text {oct }}$ are determined by curve fitting of the XANES spectra of the samples to simulated spectra obtained by the linear combination of spectra of TS-1 $\left(\mathrm{T}_{\mathrm{tet}}\right)$ and $\mathrm{TiO}_{2}\left(\mathrm{~T}_{\mathrm{oct}}\right)$. Their best fitted curves are shown in Fig. 3 (dotted lines), and thus-obtained ratios of $\mathrm{T}_{\text {tet }}$ to $\mathrm{T}_{\text {tet }}$ and $\mathrm{T}_{\mathrm{oct}}$ $\left(\mathrm{T}_{\text {tet }} /\left(\mathrm{T}_{\text {tet }}+\mathrm{T}_{\mathrm{oct}}\right)\right)$ are summarized in Table 2. It is reasonable that $\mathrm{T}_{\text {tet }} /\left(\mathrm{T}_{\text {tet }}+\mathrm{T}_{\mathrm{oct}}\right)$ is almost reciprocal to $\mathrm{C}_{\mathrm{Ti}}$; w- $\mathrm{Ti}(44) / \mathrm{SiO}_{2}$, having the lowest $\mathrm{C}_{\mathrm{Ti}}$, included mainly $\mathrm{T}_{\text {tet }}$, but higher loading of $\mathrm{Ti}$ induced aggregation between $\mathrm{Ti}$ atoms and thereby the $\mathrm{T}_{\text {tel }} /\left(\mathrm{T}_{\text {tet }}+\mathrm{T}_{\text {oct }}\right)$ halved in samples with the highest Ti content (w-Ti(528)/SiO 2$)$.

Figure 4 shows plots of TON and $\mathrm{E}_{\mathrm{fH} 2 \mathrm{O} 2}$ as a function of $\mathrm{T}_{\mathrm{tet}} /\left(\mathrm{T}_{\mathrm{tet}}+\mathrm{T}_{\mathrm{oct}}\right)$. Both TON and $\mathrm{E}_{\mathrm{fH} 2 \mathrm{O} 2}$ monotonically increased with increase in $\mathrm{T}_{\mathrm{tet}} /\left(\mathrm{T}_{\mathrm{tet}}+\mathrm{T}_{\mathrm{oct}}\right)$. Except for side reactions, e.g., ring-opening of epoxide (see below), the main chemical events in the present system are assumed to be (1) formation of epoxide from 1-octene with $\mathrm{H}_{2} \mathrm{O}_{2}$ and (2) decomposition of $\mathrm{H}_{2} \mathrm{O}_{2}$ presumably into molecular oxygen $\left(\mathrm{O}_{2}\right)$. Although it is practically impossible to analyze such events on titanium sites, $T_{\text {tet }}$ and $\mathrm{T}_{\mathrm{oct}}$, independently, the present results suggest that $\mathrm{T}_{\text {tet }}$ mainly works as active sites for epoxide formation and that $\mathrm{T}_{\text {oct }}$ is relatively more active for the decomposition of $\mathrm{H}_{2} \mathrm{O}_{2}$.

It should be noted that there was no appreciable activity on the hydrophilic w- $\mathrm{Ti}(158) / \mathrm{SiO}_{2}$ catalyst with low $\mathrm{C}_{\mathrm{Ti}}$ that included $\mathrm{T}_{\text {tet }}$ as a main component of $\mathrm{Ti}$ species even though thorough mechanical agitation to drive mass transfer was provided (Table 1, entry 3). Therefore, for the use of phase-boundary catalytic 
systems, additional structural features of active site(s), e.g., effective location of titanium sites on the surface of w/o- $\mathrm{Ti}\left(\mathrm{C}_{\mathrm{Ti}}\right) / \mathrm{SiO}_{2}$, having both hydrophobic and hydrophilic faces, and local environment of $\mathrm{T}_{\text {tet }}$ after modification with alkylsilyl groups, should also be taken in consideration.

\section{Role of Alkylsilyl groups in selective production of epoxide.}

To obtain further information on the structure of active sites on the catalysts after modification with alkylsilyl groups $\left(\mathrm{w} / \mathrm{o}-\mathrm{Ti}\left(\mathrm{C}_{\mathrm{Ti}}\right) / \mathrm{SiO}_{2}\right)$, DR spectra were compared with the spectrum of $\mathrm{w}-\mathrm{Ti}\left(\mathrm{C}_{\mathrm{Ti}}\right) / \mathrm{SiO}_{2}$, i.e., the sample without modification with alkylsilyl groups. Figure 5 shows DR spectra of samples of $\mathrm{C}_{\mathrm{Ti}}$ of 158 with and without modification. In order to avoid the collapse of surface alkylsilyl groups on w/o- $\mathrm{Ti}(158) / \mathrm{SiO}_{2}$, both spectra were obtained after pretreatment at relatively low temperature $(423 \mathrm{~K})$ in comparison with the spectra shown in Fig. 2, those of which were obtained after pretreatment at $573 \mathrm{~K}$. However, based on the facts that there is no difference in the spectra of $\mathrm{w}-\mathrm{Ti}(158) / \mathrm{SiO}_{2}$ between these pretreatment conditions, differences of water adsorption and/or hydration level, if present, should not influence the DR spectra. It is clear from this figure that modification results in no appreciable broadening and/or shift of the spectrum to a longer wavelength range, indicating that the coordination number of titanium species was not affected by the modification, i.e., aggregation between isolated titanium species ( $\left.\mathrm{T}_{\text {tet }}\right)$ was not induced, and $\mathrm{T}_{\text {tet }} /\left(\mathrm{T}_{\text {tet }}+\mathrm{T}_{\mathrm{oct}}\right)$ might therefore not be changed by the modification. ${ }^{14}$ One of the most notable features shown in Fig. 5 is that the w/o- $\mathrm{Ti}(158) / \mathrm{SiO}_{2}$ gave two absorption peaks centered at the wavelengths of ca. 210 $\mathrm{nm}\left(\mathrm{A}_{210}\right)$ and ca. $230 \mathrm{~nm}\left(\mathrm{~A}_{230}\right)$. Such absorption peaks have also been observed in dehydrated TS-1 and attributed to two different framework sites as $\left[\mathrm{Ti}(\mathrm{OH})(\mathrm{OSi})_{3}\right]$ and $\left[\mathrm{Ti}(\mathrm{OSi})_{4}\right],{ }^{15}$ though their assignment to two peaks has not been fixed yet. Moreover, as has been reported by Machese et al., there were two kinds of 
tetrahedral titanium sites in Ti-MCM-41 that were detected by photoluminescence measurements. ${ }^{16}$ Therefore, the two peaks in Fig. 5 are attributable to titanium sites in different tetrahedral environments. Based on the fact that $A_{230}$ is similar to the predominant peak of the w- $\mathrm{Ti}(158) / \mathrm{SiO}_{2}$ sample with no alkylsilyl groups (Fig. 5a), the peak may correspond to the tetrahedral titanium site having a hydroxyl group $\left(\mathrm{Ttet}(\mathrm{OH})\right.$ ) (Fig. 6a, left (i)). On the other hand, since $\mathrm{A}_{210}$ appeared also in the spectrum of the silica-coated $\mathrm{w}-\mathrm{Ti}(158) / \mathrm{SiO}_{2}$ sample, i.e., this peak seemed to appear only when a Ti unit is covered by -O-Si-O- shells, $\mathrm{A}_{210}$ is attributable to the species formed via reaction of a hydroxyl group on the tetrahedral titanium site (Ti-OH) with ODMS ( $\mathrm{T}_{\text {tet }}(\mathrm{OSiR})$, see Fig. 6b, right (ii)).

In order to represent the distribution of these $T_{\text {tet }}$ sites shown in Fig. 6a semi-quantitatively, the ratio of $\mathrm{KM}$ function at $210 \mathrm{~nm}$ to that at $230 \mathrm{~nm}$ $\left(\mathrm{KM}_{210} / \mathrm{KM}_{230}\right)$ was introduced for convenience. Table 3 summarizes the calculated $\mathrm{KM}_{210} / \mathrm{KM}_{230}$ values of the w/o- $\mathrm{Ti}\left(\mathrm{C}_{\mathrm{Ti}}\right) / \mathrm{SiO}_{2}$ and $\mathrm{w}-\mathrm{Ti}(158) / \mathrm{SiO}_{2}$ samples together with the selectivity of 1-octene epoxidation, defined as the percentage of epoxide yield in total amount of products. In order to exclude the influence of aggregated titanium species $\left(\mathrm{T}_{\text {oct }}\right)$ on the activity (Table 2 ), samples with ca. 120-160 $\mu \mathrm{mol} \mathrm{g} \mathrm{g}^{-1}$ of $\mathrm{C}_{\mathrm{Ti}}$, giving similar $\mathrm{T}_{\text {tet }} /\left(\mathrm{T}_{\text {tet }}+\mathrm{T}_{\text {oct }}\right)$ in this table were selected. Compared to w-Ti(158)/ $\mathrm{SiO}_{2}$, i.e., without ODMS modification, modified samples showed increment in $\mathrm{KM}_{210} / \mathrm{KM}_{230}$ up to almost unity, indicating the formation of $\mathrm{T}_{\text {tet }}(\mathrm{OSiR})$ sites due to the modification. It should be noted, however, that a few samples showed relatively small or almost no increment in $\mathrm{KM}_{210} / \mathrm{KM}_{230}$ due to modification with alkylsilyl groups even though the same ODMS treatment was conducted (entries 3 and 4). Such differences in the $\mathrm{KM}_{210} / \mathrm{KM}_{230}$ values could not be elucidated and controlled at present, probably because these differences were caused by subtle unexpected differences in experimental conditions, e.g., humidity and contaminants in solvents. Anyway, among the w/o- $\mathrm{Ti}\left(\mathrm{C}_{\mathrm{Ti}}\right) / \mathrm{SiO}_{2}$ samples with 
different values of $\mathrm{KM}_{210} / \mathrm{KM}_{230}$, the higher $\mathrm{KM}_{210} / \mathrm{KM}_{230}$ was, the higher was the product selectivity. These results indicate that the $\mathrm{T}_{\text {tet }}(\mathrm{OSiR})$ site was an active site for selective epoxide formation.

\section{Local structure of active sites for PBC.}

A possible model for the active titanium sites was considered on the basis of the above discussion, and the overall structures of them on the w/o- $\mathrm{Ti}\left(\mathrm{C}_{\mathrm{Ti}}\right) / \mathrm{SiO}_{2}$ are illustrated in Fig. 6. Similar to previously reported NaY zeolite-based samples, w/o- $\mathrm{Ti}\left(\mathrm{C}_{\mathrm{Ti}}\right) / \mathrm{SiO}_{2}$ might have both hydrophobic and hydrophilic faces. Thus, the loaded $\mathrm{T}_{\text {tet }}$ was categorized into two groups: one on the hydrophilic surface $\left(\mathrm{T}_{\mathrm{tet}}(\mathrm{OH}, \mathrm{w})\right)$ and the other on the hydrophobic surface of silica. Moreover, the above-described results suggest that the $\mathrm{T}_{\text {tet }}$ on the hydrophobic surface could be divided into two groups of sites: sites with no binding with alkylsilyl groups $\left(\mathrm{T}_{\text {tet }}(\mathrm{OH}, \mathrm{o})\right)$ and sites directly bound to alkylsilyl groups $\left(\mathrm{T}_{\text {tet }}(\mathrm{OSiR})\right)$. From the fact that there was no appreciable activity on w- $\mathrm{Ti}\left(\mathrm{C}_{\mathrm{Ti}}\right) / \mathrm{SiO}_{2}$ containing only $\mathrm{T}_{\text {tet }}(\mathrm{OH}, \mathrm{w})$ even with vigorous stirring (Table 1 , entry 3$), \mathrm{T}_{\text {tet }}(\mathrm{OH}, \mathrm{w})$ on w/o- $\mathrm{Ti}\left(\mathrm{C}_{\mathrm{Ti}}\right) / \mathrm{SiO}_{2}$ samples is thought to be inactive, probably owing to their less accessibility and low adsorption affinity to the substrate (1-octene). On the other hand, $\mathrm{T}_{\text {tet }}(\mathrm{OH}, \mathrm{o})$ on the hydrophobic surface of the present $\mathrm{PBC}\left(\mathrm{w} / \mathrm{o}-\mathrm{Ti}\left(\mathrm{C}_{\mathrm{Ti}}\right) / \mathrm{SiO}_{2}\right)$ is thought to be active because appreciable activity was seen even in the absence of or with only a small amount of $\mathrm{T}_{\text {tet }}(\mathrm{OSiR})$ (Table 3, entry 4). Corma et al. reported that the presence of $\equiv \mathrm{Ti}$-OH groups in Ti-zeolite allows adsorption of the product epoxide due to its higher polarity than that of olefinic substrates, resulting in a ring opening of epoxide to diols. ${ }^{17}$ The $\mathrm{T}_{\text {tet }}(\mathrm{OH}, \mathrm{o})$ site, therefore, could induce a ring-opening reaction to yield 1,2-octanediol. Due to the absence of such acidic hydroxyl in the neighborhood, $\mathrm{T}_{\text {tet }}(\mathrm{OSiR})$ on the hydrophobic surface is thought to be an active site for selective production of epoxides. It is also probable to induce such ring opening 
reaction on the surface $\mathrm{Si}-\mathrm{OH}$. However, there was no production of the diol when the catalyst with high $\mathrm{T}_{\text {tet }}(\mathrm{OSiR})$ was used even though the presence of $\mathrm{Si}-\mathrm{OH}$. Moreover, the diol was not produced when the mixture of epoxides, hydrogen peroxide, and $\mathrm{SiO}_{2}$ particles without loading of titanium was stirred at room temperature. Therefore, the diol liberation was only induced on Ti-OH in the present phase-boundary catalytic system.

\section{Conclusions}

The local structure of titanium oxide species on silica for phase-boundary catalytic epoxidation of 1-octene with aqueous hydrogen peroxide was investigated. It has been proved that 4-coordinated titanium oxide species directly attached to alkylsilane $\left(\mathrm{T}_{\text {tet }}(\mathrm{OSiR})\right)$ on the hydrophobic face of the bimodal particle is an active site for selective production of 1,2-epoxyoctane but that two other kinds of titanium species are inactive or active but non-selective for epoxide formation, inducing ring opening to yield 1,2-octanediol. At present, some extent of titanium atom could be loaded on silica as the site of a promising structure, $\mathrm{T}_{\text {tet }}(\mathrm{OSiR})$, for selective production of epoxide. Therefore, further improvement for selective loading of the $\mathrm{T}_{\text {tet }}(\mathrm{OSiR})$ site is expected. Although, in the present study, we used 1-octene as a sole substrate and the observed activity was not so high, there should be several substrates that can be used for the present phase-boundary catalytic oxidation with $\mathrm{H}_{2} \mathrm{O}_{2}$ and, actually, we have already found some reactions could be catalyzed efficiently in this system. Thus, further investigations along these lines are under way.

\section{Acknowledgements}

The authors are grateful to Nippon Aerosil Co., Ltd. for supplying silica samples. Mr. Tetsuzo Habu and Mr. Kazuhiro Matsudaira (Technical Division of the 
Catalysis Research Center, Hokkaido University) are acknowledged for their assistance in the construction of the XAFS cells and the reaction apparatus.

\section{References}

1. M. Dusi, T. Mallat and A. Baiker, Catal. Rev. Sci. Eng., 2000, 42, 213-278.

2. A. Bhaumik and R. Kumar, J. Chem. Soc. Chem. Commun., 1995, 349-350.

3. T. Tatsumi, K. A. Koyano and N. Igarashi, Chem. Commun., 1998, 325-326.

4. A. Bhaumik, P. Mukherjee and R. Kumar, J. Catal., 1998, 178, 101-107.

5. H. Nur, S. Ikeda and B. Ohtani, Chem. Commun., 2000, 2235-2236.

6. H. Nur, S. Ikeda and B. Ohtani, J. Catal., 2001, 204, 402-408.

7. S. Ikeda, H. Nur, T. Sawadaishi, K. Ijiro, M. Shimomura and B. Ohtani, Langmuir, 2001, 17, 7976-7979.

8. M. Nomura and A. Koyama, Nucl. Insturm. Meth. A, 2001, 467-468,733-736.

9. S. Ikeda, K. Ikeue and B. Ohtani, to be published.

10. J. Jarupatrakom and T. D. Tilley, J. Am. Chem. Soc., 2002, 124, 8380-8388.

11. C. Lamberti, S. Bordiga, D. Arduino, A. Zecchina, F. Geobaldo, G. Spanò, F. Genoni, G. Petrini, A. Carati, F. Villain and G. Vlaic, J. Phys. Chem. B, 1998, 102, 6382-6390.

12. M. Raimondi, E. Gianotti, L. Marchese, G. Martra, T. Maschmeyer, J. M. Seddon and S. Coluccia, J. Phys. Chem. B, 2000, 104, 7102-7109.

13. K. Ikeue, H. Mukai, H. H. Yamashita, S. Inagaki and M. Anpo, J. Syncrotron Rad., 2001, 8, 640-642.

14. To exclude the influence of the coordination of water molecules onto Ttet, XAFS should be measured after pretreatment under vacuum at $>573 \mathrm{~K}$. However, due to the presence of alkyl groups on w/o- $\mathrm{Ti}\left(\mathrm{C}_{\mathrm{Ti}}\right) / \mathrm{SiO}_{2}$, such pretreatment at a high temperature might result in decomposition of them. 
Therefore, the coordination number of titanium oxide species on w/o- $\mathrm{Ti}\left(\mathrm{C}_{\mathrm{Ti}}\right) / \mathrm{SiO}_{2}$ could not be accurately determined by XAFS measurement.

15. L. Le-Noc, D. Trong-On, S. Solomykina, B. Echchahed, F. Beland, D. Cartier dit Moulin and L. Bonneviot, Stud. Surf. Sci. Catal., 1996, 101, 611-620.

16. L. Marchese, T. Maschmeyer, E. Gianotti, S. Coluccia and J. M. Thomas, J. Phys. Chem. B, 1997, 101, 8836-8838.

17. A. Corma, M. Domine, J. A. Gaona, J. L. Jordá, M. T. Navarro, F. Rey, J. Pérez-Pariente, J. Tsuji, B. McCulloch and L. T. Nemeth, Chem. Commun, $1998,2211-2212$. 


\section{Figure captions}

Fig. 1. Photographs of $w / o-\mathrm{Ti}\left(\mathrm{C}_{\mathrm{Ti}}\right) / \mathrm{SiO}_{2}$ and $\mathrm{w}-\mathrm{Ti}\left(\mathrm{C}_{\mathrm{Ti}}\right) / \mathrm{SiO}_{2}$ samples in a 1-octene/aqueous $\mathrm{H}_{2} \mathrm{O}_{2}(30 \%)$ binary system.

Fig. 2. (a) Representative diffuse reflectance (DR) spectra of $w-T i\left(C_{\mathrm{Ti}}\right) / \mathrm{SiO}_{2}$ samples and (b) those normalized at $230 \mathrm{~nm}$. Titanium contents $\left(\mathrm{C}_{\mathrm{Ti}} / \mu \mathrm{mol} \mathrm{g}-1\right)$ were (1) 75 , (2) 158 , and (3) 528. All spectra were measured after evacuation at $573 \mathrm{~K}$ for $3 \mathrm{~h}$.

Fig. 3. Representative $\mathrm{Ti}$ K-edge XANES spectra of several titanium oxide-containing samples. (a) $\mathrm{TiO}_{2}$ (Degussa P-25), (b) TS-1, (c) w-Ti(528)/ $/ \mathrm{SiO}_{2}$, (d) $\mathrm{w}-\mathrm{Ti}(158) / \mathrm{SiO}_{2}$. Dotted lines represent simulated spectra obtained by linear combination of spectra (a) and (b). Before measurements, all samples were degassed by evacuation at $573 \mathrm{~K}$ for $3 \mathrm{~h}$.

Fig. 4. Plots of $\mathrm{TON}$ and $\mathrm{E}_{\mathrm{fH} 2 \mathrm{O} 2}$ as a function of $\mathrm{T}_{\mathrm{tet}} /\left(\mathrm{T}_{\mathrm{tet}}+\mathrm{T}_{\text {oct }}\right)$. Titanium contents $\left(\mathrm{C}_{\mathrm{Ti}} / \mu \mathrm{mol} \mathrm{g}{ }^{-1}\right)$ were (1) 44, (2) 75 , (3) 158 , (4) 333, and (5) 528.

Fig. 5. DR spectra of (a) w- $\mathrm{Ti}(158) / \mathrm{SiO}_{2}$ and (b) w/o-Ti(158)/ $\mathrm{SiO}_{2}$. All spectra were measured after evacuation at $423 \mathrm{~K}$ for $3 \mathrm{~h}$.

Fig. 6. Schematic illustrations of (a) the local structure and (b) the distribution of tetrahedral titanium oxide species on w/o- $\mathrm{Ti}\left(\mathrm{C}_{\mathrm{Ti}}\right) / \mathrm{SiO}_{2}$ samples. (i) $\mathrm{T}_{\text {tet }}(\mathrm{OSiR})$ sites located on the hydrophobic surface with an absorption peak at ca. $210 \mathrm{~nm}$, (ii) $\mathrm{T}_{\text {tet }}(\mathrm{OH})$ sites located on both hydrophilic and hydrophobic surfaces $\left(\mathrm{T}_{\text {tet }}(\mathrm{OH}, \mathrm{w})\right.$ and $\mathrm{T}_{\text {tet }}(\mathrm{OH}, \mathrm{o})$, respectively) giving absorption centered at ca. $230 \mathrm{~nm}$. 
Table 1. Effect of agitation on the yield of epoxide by titanium-loaded silica particles $^{\mathrm{a}}$

\begin{tabular}{|c|c|c|c|c|c|c|c|}
\hline \multirow{3}{*}{ entry } & \multirow{3}{*}{ catalyst } & \multicolumn{6}{|c|}{ yield / $\mu$ mol } \\
\hline & & \multicolumn{3}{|l|}{ static $^{\mathrm{b}}$} & \multicolumn{3}{|l|}{ stirring $^{\mathrm{c}}$} \\
\hline & & epoxide $^{\mathrm{d}}$ & diol $^{\mathrm{e}}$ & others $^{\mathrm{f}}$ & epoxide $^{\mathrm{d}}$ & $\mathrm{diol}^{\mathrm{e}}$ & others ${ }^{\mathrm{f}}$ \\
\hline 1 & w/o- $\mathrm{Ti}(158) / \mathrm{SiO}_{2}$ & 72.8 & $0^{\mathrm{g}}$ & $0^{\mathrm{g}}$ & 87.1 & 4.2 & 2.7 \\
\hline 2 & w/o- $\mathrm{Ti}(333) / \mathrm{SiO}_{2}$ & 41.9 & 3.9 & 1.1 & 16.7 & 10.8 & 8.5 \\
\hline 3 & $\mathrm{w}-\mathrm{Ti}(158) / \mathrm{SiO}_{2}$ & 0.3 & $0^{\mathrm{g}}$ & 0.1 & 0.5 & $0^{\mathrm{g}}$ & 0.2 \\
\hline
\end{tabular}

${ }^{\mathrm{a}}$ All reactions were carried out at $298 \mathrm{~K}$ for $20 \mathrm{~h}$ with 1-octene $\left(4 \mathrm{~cm}^{3}\right), 30 \% \mathrm{H}_{2} \mathrm{O}_{2}(1$ $\mathrm{cm}^{3}$ ) and catalyst $(50 \mathrm{mg}) .{ }^{\mathrm{b}}$ Reaction was carried out under static condition. ${ }^{\mathrm{c}}$ Reaction was carried out with vigorous mechanical agitation. ${ }^{\mathrm{d}} 1,2$-Epoxyoctane. ${ }^{\mathrm{e}} 1,2$-Octanediol. ${ }^{\mathrm{f}}$ 1-Octanol and 2-octanol. ${ }^{\mathrm{g}}$ Not detected $\left(<10^{-3} \mu \mathrm{mol}\right)$. 
Table 2. Dependence of activity for epoxidation of 1-octene with $\mathrm{H}_{2} \mathrm{O}_{2}$ on titanium contents in various w/o- $\mathrm{Ti}\left(\mathrm{C}_{\mathrm{Ti}}\right) / \mathrm{SiO}_{2}$ samples $^{\mathrm{a}}$

\begin{tabular}{|c|c|c|c|c|c|c|c|}
\hline \multirow{2}{*}{ entry } & \multirow{2}{*}{ catalyst } & \multirow{2}{*}{$\mathrm{T}_{\text {tet }} /\left(\mathrm{T}_{\text {tet }}+\mathrm{T}_{\text {oct }}\right)^{\mathrm{b}}$} & \multicolumn{3}{|c|}{ yield / $\mu$ mol } & \multirow{2}{*}{ TON } & \multirow{2}{*}{$\begin{array}{l}\mathrm{Ef}_{\mathrm{H} 2 \mathrm{O} 2}{ }^{\mathrm{f}} \\
1 \%\end{array}$} \\
\hline & & & epoxide $^{c}$ & $\operatorname{diol}^{\mathrm{d}}$ & others $^{\mathrm{e}}$ & & \\
\hline 1 & w/o- $\mathrm{Ti}(44) / \mathrm{SiO}_{2}$ & 0.95 & 27.5 & 0 & 0 & 12.6 & 53 \\
\hline 2 & w/o- $\mathrm{Ti}(75) / \mathrm{SiO}_{2}$ & 0.89 & 36.6 & 0 & 0 & 9.7 & 46 \\
\hline 3 & w/o- $\mathrm{Ti}(158) / \mathrm{SiO}_{2}$ & 0.81 & 72.8 & 0 & 0 & 9.2 & 33 \\
\hline 4 & w/o- $\mathrm{Ti}(333) / \mathrm{SiO}_{2}$ & 0.57 & 41.9 & 3.9 & 1.1 & 2.5 & 14 \\
\hline 5 & w/o- $\mathrm{Ti}(528) / \mathrm{SiO}_{2}$ & 0.55 & 39.7 & 6.5 & 1.6 & 1.5 & 5 \\
\hline
\end{tabular}

${ }^{\mathrm{a}}$ Reaction conditions are the same as those given for Table $1 .{ }^{\mathrm{b}}$ Ratio of the content of 4-coordinated titanium oxide $\left(\mathrm{T}_{\text {tet }}\right)$ to the sum of $\mathrm{T}_{\text {tet }}$ and that of 6-coordinated one $\left(\mathrm{T}_{\mathrm{oct}}\right) .{ }^{\mathrm{c}}$ 1,2-Epoxyoctane. ${ }^{\mathrm{d}}$ 1,2-Octanediol. ${ }^{\mathrm{e}}$ 1-Octanol and 2-octanol. ${ }^{\mathrm{f}}$ Efficiency of $\mathrm{H}_{2} \mathrm{O}_{2}$ utilization defined as the percentage of the epoxide yield to amount of consumed and decomposed $\mathrm{H}_{2} \mathrm{O}_{2}$. 
Table 3. Selectivity of epoxidation of 1-octene with $\mathrm{H}_{2} \mathrm{O}_{2}$ by w/o- $\mathrm{Ti}\left(\mathrm{C}_{\mathrm{Ti}}\right) / \mathrm{SiO}_{2}{ }^{a}$ and ratio of Kubelka-Munk fanctions

\begin{tabular}{|c|c|c|c|c|c|c|}
\hline \multirow{2}{*}{ entry } & \multirow{2}{*}{ catalyst } & \multicolumn{3}{|c|}{ yield / $\mu \mathrm{mol}$} & \multirow{2}{*}{$\begin{array}{l}\text { selectivity }^{\mathrm{e}} \\
/ \%\end{array}$} & \multirow{2}{*}{$\mathrm{KM}_{210} / \mathrm{KM}_{230}{ }^{\mathrm{f}}$} \\
\hline & & epoxide $^{\mathrm{b}}$ & $\operatorname{diol}^{\mathrm{c}}$ & others $^{\mathrm{d}}$ & & \\
\hline 1 & w/o- $\mathrm{Ti}(122) / \mathrm{SiO}_{2}$ & 55.6 & 0 & 0 & 100 & 1.00 \\
\hline 2 & w/o- $\mathrm{Ti}(158) / \mathrm{SiO}_{2}$ & 72.8 & 0 & 0 & 100 & 1.01 \\
\hline 3 & w/o- $\mathrm{Ti}(131) / \mathrm{SiO}_{2}$ & 61.3 & 3.0 & 1.6 & 93 & 0.97 \\
\hline 4 & w/o- $\mathrm{Ti}(159) / \mathrm{SiO}_{2}$ & 50.2 & 7.5 & 1.7 & 85 & 0.93 \\
\hline 5 & $\mathrm{w}-\mathrm{Ti}(158) / \mathrm{SiO}_{2}$ & 0.3 & 0 & 0.1 & 75 & 0.90 \\
\hline
\end{tabular}

${ }^{\mathrm{a}}$ Reaction conditions are the same as those given for Table 1. ${ }^{\mathrm{b}} 1,2$-Epoxyoctane. ${ }^{\mathrm{c}} 1,2$-Octanediol. ${ }^{\mathrm{d}} 1$-Octanol and 2-octanol ${ }^{\mathrm{e}}$ Selectivity defined as the percentage of the yield of epoxide to other by-products. ${ }^{\mathrm{f}}$ Ratio of K-M function at $210 \mathrm{~nm}$ to that at 230 nm. 


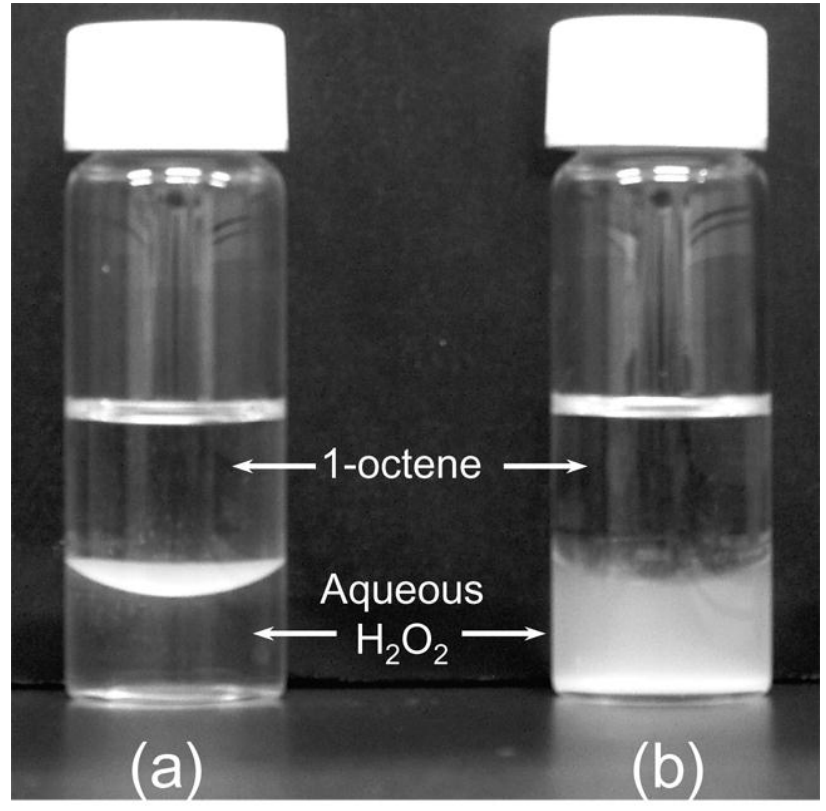

Figure 1. K. Ikeue et al. 


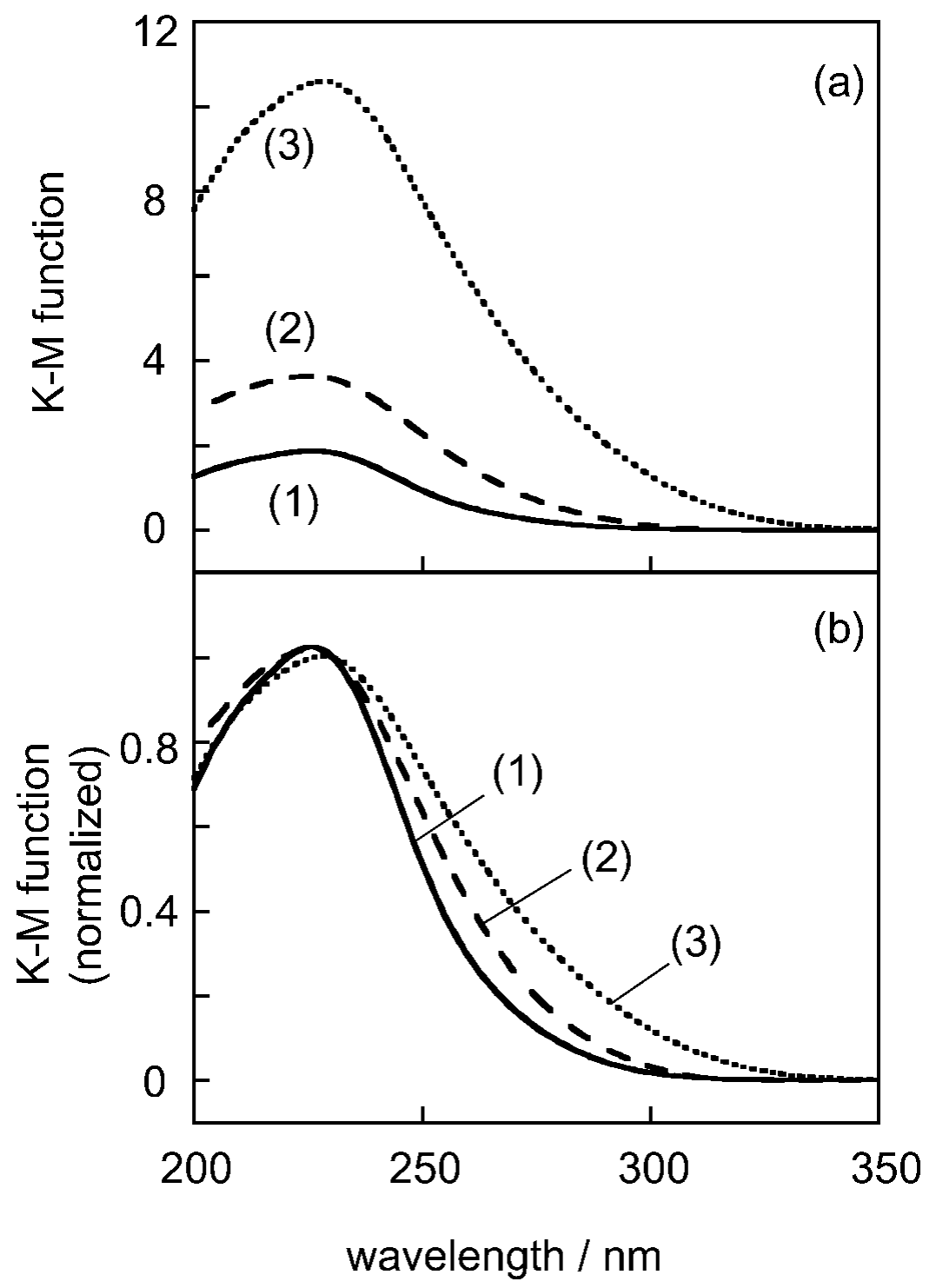

Figure 2. K. Ikeue et al. 


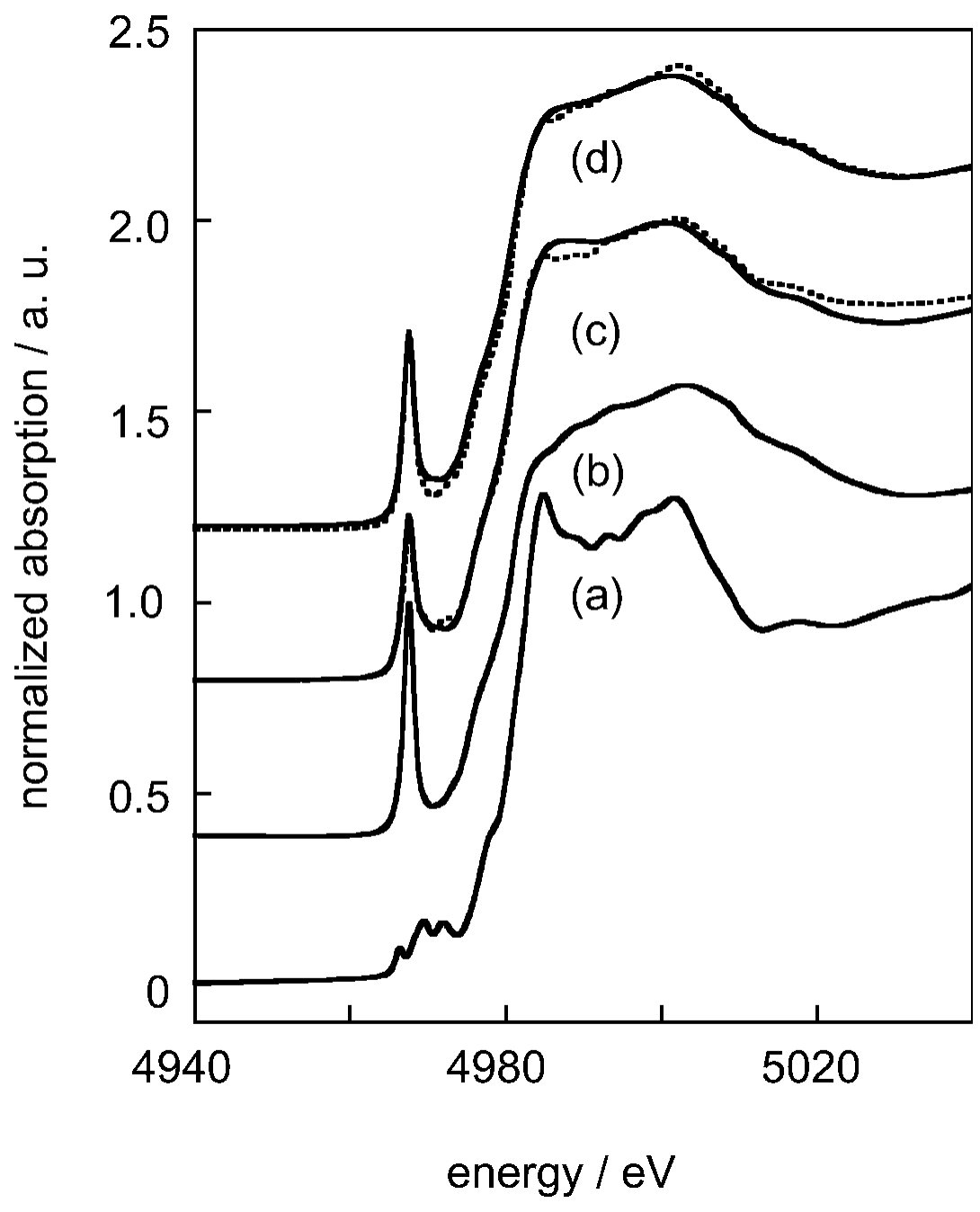

Figure 3. K. Ikeue et al. 


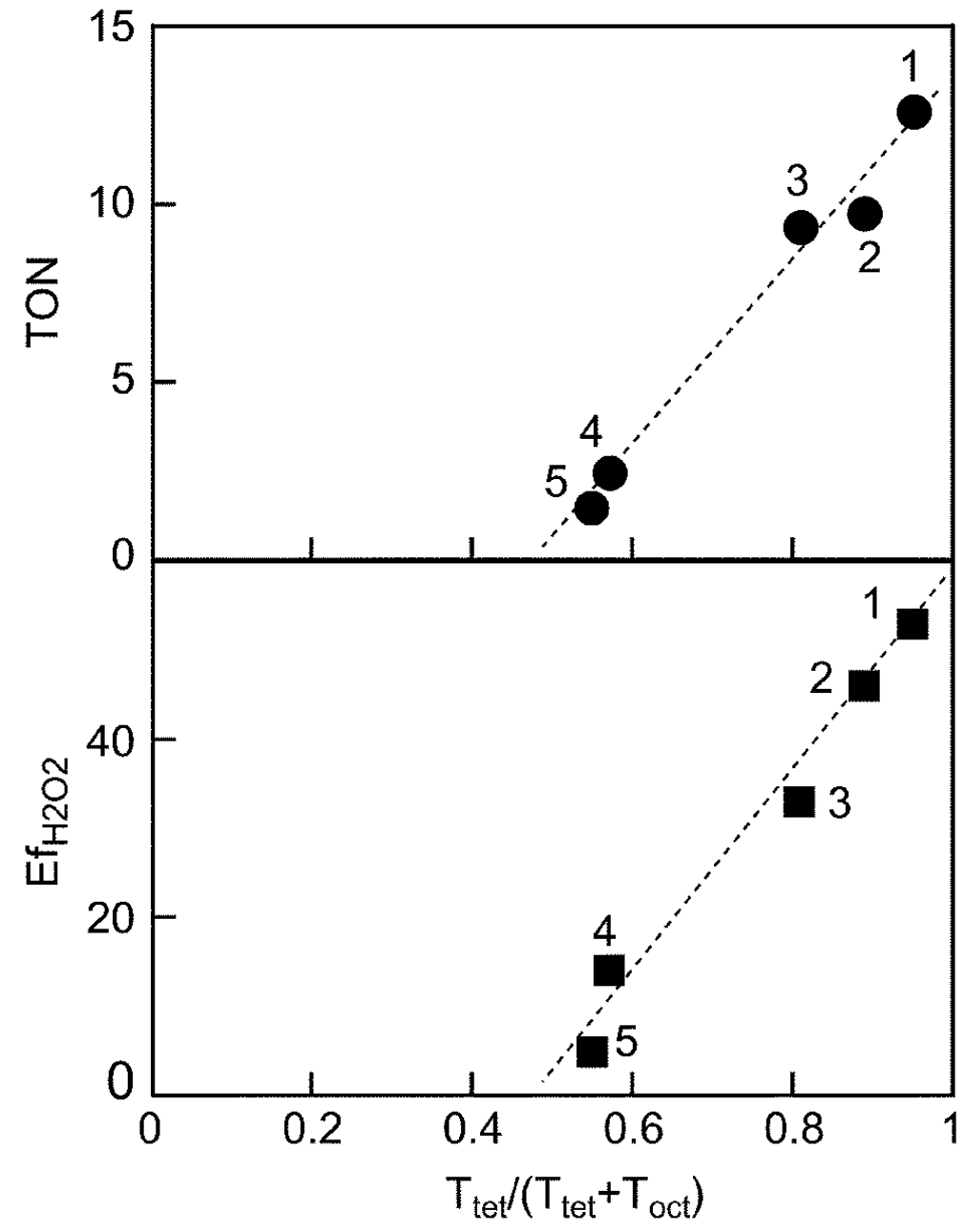

Figure 4. K. Ikeue et al. 


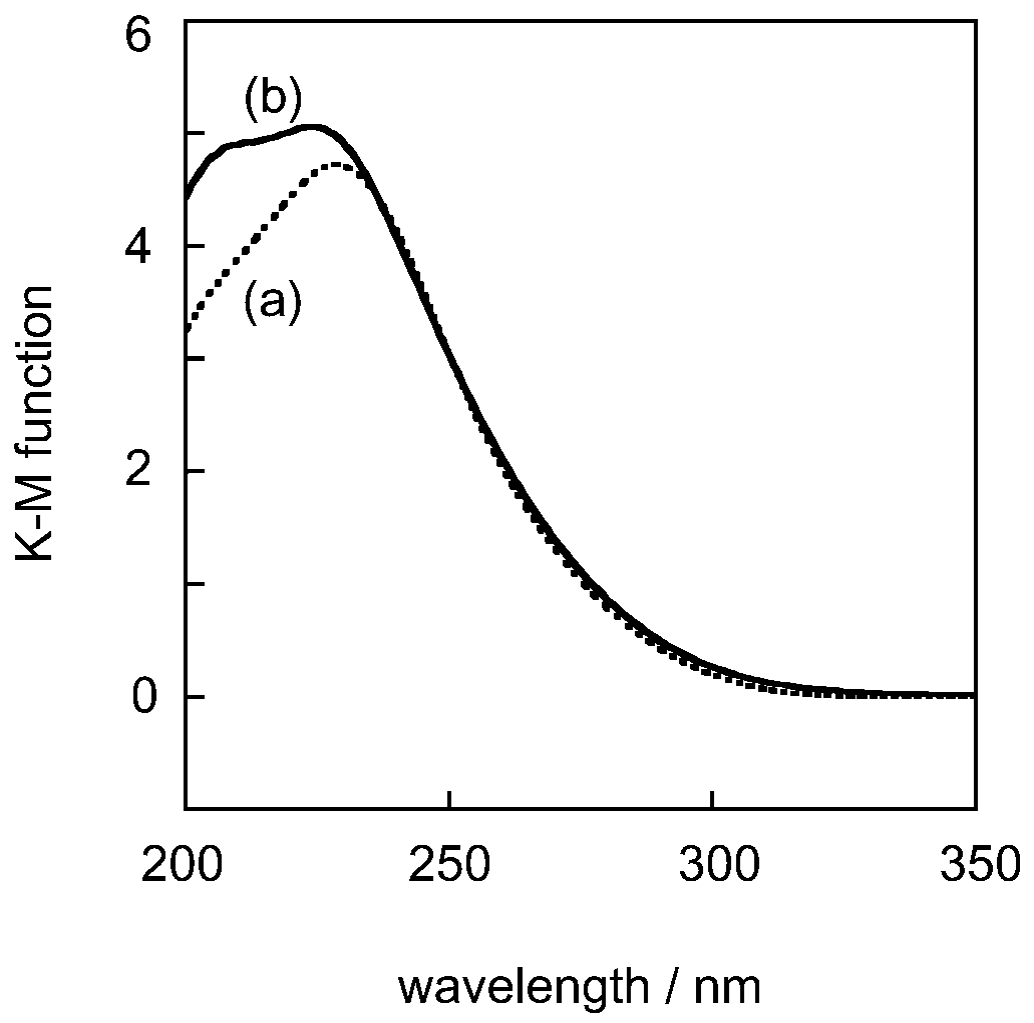

Figure 5. K. Ikeue et al. 
(a)

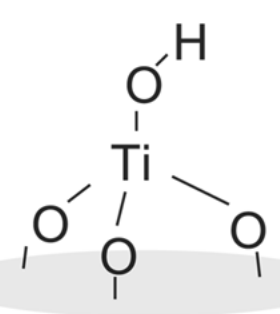

(i) $\mathrm{T}_{\text {tet }}(\mathrm{OH})$

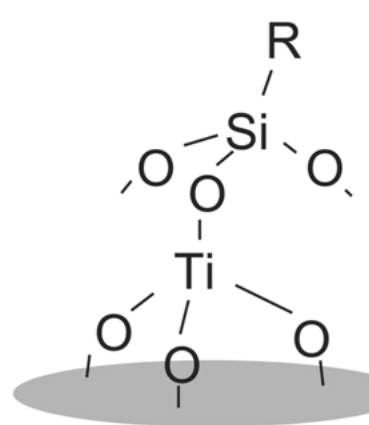

(ii) $T_{\text {tet }}(\mathrm{OSiR})$

(b)

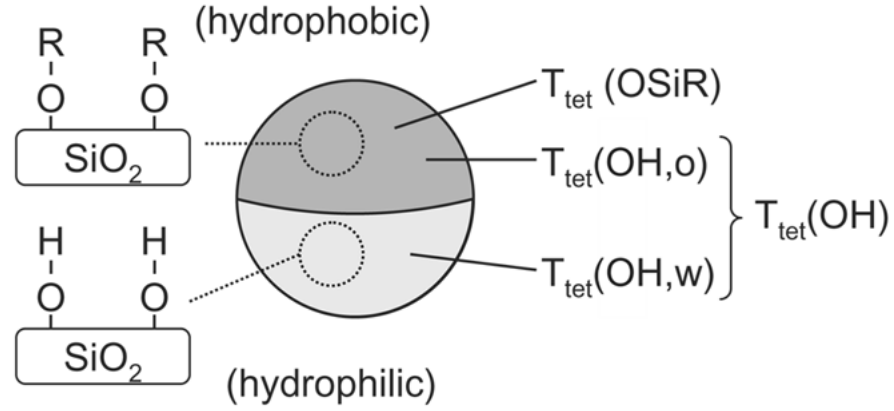

Figure 6. K. Ikeue et al. 